\title{
$\mathrm{Ti} / \mathrm{Al}$ 比の異なる TiAl 粉末の射出成形
}

\author{
加藤 清隆々1, 松本 章宏々1, 野崎 佳彦々2, 家城 悌々3

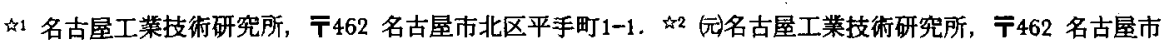

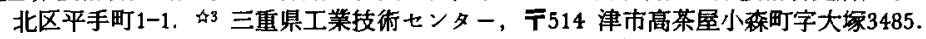

\section{Metal Injection Molding of Pre-alloyed TiAl Powders with Various Ti/Al Ratios}

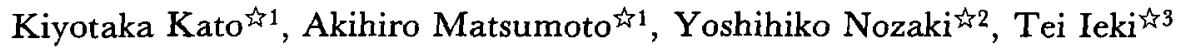 \\ भf 1 National Industrial Research Institute of Nagoya, 1-1 Hirate-cho Kita-ku, Nagoya 462. 敌 National Industrial \\ Research Institute of Nagoya, 1-1 Hirate-cho Kita-ku, Nagoya 462. ths The Mie Industrial Research Institute, \\ 3485 Takachaya-komori-cho, Tsu 514.
}

Received March 30, 1994

\section{SYNOPSIS}

Sintered binary $\mathrm{Ti}-\mathrm{Al}$ compacts with various $\mathrm{Ti} / \mathrm{Al}$ ratios prepared by metal injection molding process were investigated. Powder materials used for this study were pre-alloyed TiAl powders (average particle size:10 $\mu \mathrm{m}$ ), which compositions were

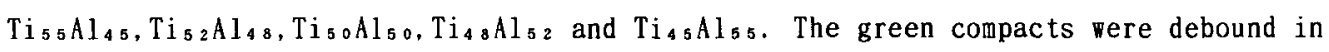
air or vacuum $\left(10^{2} \mathrm{~Pa}\right.$ order $)$. Subsequently, they were sintered at $1648 \mathrm{~K}$ for $7.2 \mathrm{ks}$ in $\operatorname{vacuum}\left(10^{-2} \mathrm{~Pa}\right)$.

Sintered densities of the compacts after air debinding were lower than that of the compacts after vacuum debinding for all compositions. Relative sintered densities of $\mathrm{Ti}_{55} \mathrm{Al}_{45}$ to $\mathrm{Ti}_{4} \mathrm{Al}_{52}$ compacts after vacuum debinding were above 96.5\%. A $\mathrm{Ti}_{45} \mathrm{Al}_{55}$ compact had lower density (94.5\%) than the others. Microstructures of the former were composed of two phases of $\gamma$ and $\alpha_{2}$. The latter showed $\gamma$-phase only. Lamellar structure was observed in the microstructures of $\mathrm{Ti}_{5} \mathrm{Al}_{45}$ to $\mathrm{Ti}_{50 \mathrm{Al}} \mathrm{I}_{\mathrm{o}}$ compacts. Tensile strength at room temperature of $\mathrm{Ti}_{55} \mathrm{Al}_{45}$ to $\mathrm{Ti}_{4} \mathrm{AA}_{52}$ compacts were in the range of approximately $350-400 \mathrm{MPa}$. $A \mathrm{Ti}_{4} \mathrm{Al}_{52}$ compact had the highest strength in all of the TiAl compacts.

KEY WORDS

binary TiAl, powder injection molding, debinding, sintering

\section{1 緒 言}

筆者らは $\mathrm{Ti}-\mathrm{Al}$ 系金属間化合物を构末射出成形法 により形状付与する研究開発を行っている。これ までは化学量論組成相当のTiAl合金粉末を原料に 用いて，本プロセスによる成形・焼結技術の開発 を行ってきだ!．その結果, 平均粒径が $10 \mu \mathrm{m}$ 程 度の微細な粉末を原料とすれば真空罟結により。
相対密度 $95 \%$ 以上の焼結体が得られることが明らか になった。

本報告ではこれまでに得られたTiA1の粉末射出成 形法に基づき,さらにTiリフチとA1リォチの 2 元系TiA1合金 粉末を原料として，本プロセスによる成形・焼結を 険討し, $\mathrm{Ti} / \mathrm{A} 1$ 比率の変化が焼結後の密度, 組織及び 強度に与える影幚について調べた。 


\section{2 実蜋方法}

実験に使用したTiAl粉末はTi ${ }_{55} \mathrm{Al}_{45}, \mathrm{Ti}_{52} \mathrm{Al}_{48}$ ， $\mathrm{Ti}_{50} \mathrm{Al}_{50} \mathrm{Ti}_{48} \mathrm{Al}_{52}, \mathrm{Ti}_{45} \mathrm{Al}_{5}{ }_{5}$ の 5 種類で，いずれも 燃焼合成法により製造され，球状化処理を施した粉 末である(東洋アルミこ㺨製造). Table 1 にこれらの粉

Table.1 Average particle size and ture densities of TiAl powders.

\begin{tabular}{|l|c|c|}
\hline & $\begin{array}{c}\text { Particle size } \\
(\mu \mathrm{m})\end{array}$ & $\begin{array}{c}\text { True density } \\
\left(\mathrm{Mg} / \mathrm{m}^{3}\right)\end{array}$ \\
\hline $\mathrm{Ti}_{55} \mathrm{Al} \mathrm{I}_{45}$ & 13.0 & 3.88 \\
\hline $\mathrm{Ti}_{52} \mathrm{Al}_{48}$ & 10.3 & 3.83 \\
\hline $\mathrm{Ti}_{50} \mathrm{Al}_{50}$ & 10.1 & 3.80 \\
\hline$\left.\mathrm{Ti}_{48} \mathrm{~A}\right|_{52}$ & 9.8 & 3.76 \\
\hline $\mathrm{Ti}_{45} \mathrm{Al} \mathrm{I}_{55}$ & 9.0 & 3.70 \\
\hline
\end{tabular}

末の平均粒径と真密度の值を示す.A1リッチになるほど 幾分細かくなる倾向を示しているか，平均粒径はい ずれも $10 \mu \mathrm{m}$ 前後であり射出成形に適当な粒度であ

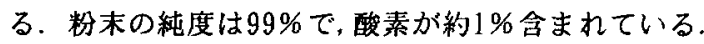
射出成形用の有機バインダーは前報”之同じくワ ックス（NE-119 中京油脂製）とアクリル系樹脂 （BR-105 三菱レーヨン製）を重量比で50\%づつ混合した ものを使用した．粉末に対するバインダー添加量は， 5 種類の粉末とも体積比で38～39vol\%が射出成形 に適正な粘度となった。前報”における角状粉末で はバインダー体積比は40\%を越えていたのに比較し て、バインダー量が減少したのは球状粉末の効果で あると思われる。

射出成形は横型スクリュー式射出成形機（三菱重

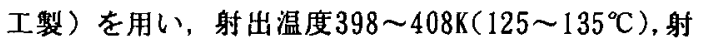
出圧力 $110 \sim 120 \mathrm{MPa}$, 射出速度 $100 \sim 120 \mathrm{~cm}^{3} / \mathrm{sec}$, 保持 压60 70M Pa $(10 \mathrm{sec})$ の条件で，板状引張試験片

（110mm×7.5mm×4mm）を作製した。

射出成形体の脱脂は加熱分解法により行い，大気 脱脂と真空脱脂の 2 種類を実験した. 真空脱脂は $10^{2} \mathrm{~Pa}$ オダーの真空度において，Arガスを流しながら 行った。脱脂最高温度は脱脂率が $90 \%$ 以上となるよ うに, 大気脱脂で $573 \mathrm{~K}\left(300^{\circ} \mathrm{C}\right)$, 真空脱脂で $648 \mathrm{~K}$ $\left(375^{\circ} \mathrm{C}\right)$ に設定した. 昇温速度はどちらむバインダー の分解温度域で $1.39 \times 10^{-3} \mathrm{~K} / \mathrm{sec}\left(5^{\circ} \mathrm{C} / \mathrm{hr}\right)$ とした。

焼結は真空中 $\left(10^{-2} \sim 10^{-3} \mathrm{~Pa}\right)$ で行った. 昇温速
度は $5.56 \times 10^{-2} \mathrm{~K} / \mathrm{sec}\left(200^{\circ} \mathrm{C} / \mathrm{hr}\right)$ ，焼結温度 $1648 \mathrm{~K}$ $\left(1375^{\circ} \mathrm{C}\right)$ で7. $2 \mathrm{ks}(2 \mathrm{hr})$ 保持後，真空を保ったまま， 室温まで冷却した。

このようにして得られた焼結体について，水アれキメ デス法による密度測定, X線回折（XRD）やX線子仍 アナラ俥”－(XMA）による組成および組穖の分析, 室温 での引張強度試験（荷重制御：19.6kN/min）ならび にビフカース硬度試験（押し込み荷重：98.IN）を実施し， 焼結体の評価を行った。

\section{1 焼結密度}

\section{3 実験結果及び考察}

Fig. 1 に1648Kで真空焼結後の焼結体の相対密度を 示す． 相対密度は本来理論密度に基つき計算すへきき であるが, 理論密度の算出が困難なため, Table 1 の 枌末の真密度の值(測定値)を $100 \%$ として計算した。 いずれの組成のTiA 1 も大気脱脂より真空脱脂による 焼結体の方が高密度となった。これは前報"で確認 されたように，脱脂による試料の酸化が原因である と考えられる：この中でも特にTi ${ }_{55} \mathrm{Al}_{45}$ と $\mathrm{Ti}_{45} \mathrm{Al}_{55}$ は両者の差が大きく酸化の影響が大きい。この結果 から，いずれの組成のTiA1でも脱脂は真空脱脂の方 が適当であると考えられる。

真空脱脂の結果を見ると, $\mathrm{Ti}_{55} \mathrm{Al}_{45}$ から $\mathrm{Ti}_{48} \mathrm{Al}_{52}$ までは相対密度が96.5\%以上となりかなり緻密化し ている，特に，Ti 50 A $1_{5}$ oはほほ98\%まで達した。 れらと比較して, AlリッチのTi $4{ }_{5} \mathrm{Al}_{5} 5_{5}$ は粉末が最も微細

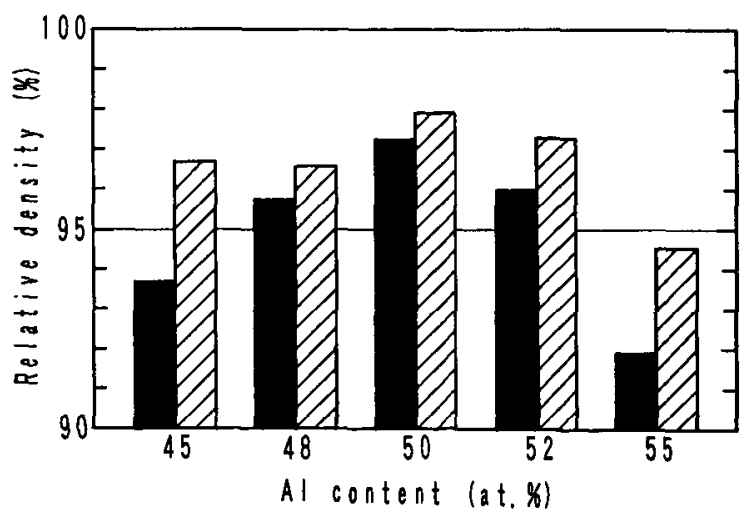

Fig.1 Relation between the relative density and the $A l$ content of sintered TiAl compacts.

Debinding atomosphere W...in air $\square$...in vacuum 
であるにもかかわらず $94.5 \%$ と密度が最も低い.プ レス成形一真空焼結によるTiAl焼結体の特性を調へ た報告 ${ }^{2)} て ゙ は ， \alpha_{2}$ 相が存在すると高温焼結時に $\alpha$ $\mathrm{Ti}$ 相が現れ，焼結性向上に寄与することを指摘して いる. $\mathrm{Ti}_{45} \mathrm{Al}_{55}$ が他に比べ焼結性が劣るのは $\gamma$ 単相 (Fig. 2参照) であることが原因の一つと考えられ る. 逆にTiリ, 千のTi ${ }_{5} \mathrm{Al}_{4}$ は $\alpha_{2}$ 量が高いため, 粉末 は最も粗いが焼結性は良い, なお, 次節以降は真空 脱脂による試料の実験結果のみを報告する.

\section{2 組織}

Fig. 2 に焼結体断面の X線回折パ夕ーンを示す. $\mathrm{Al}_{1}$ 甲のの $\mathrm{Ti}_{45} \mathrm{Al}_{5}$ は $\gamma$ 単相, $\mathrm{Ti}_{48} \mathrm{Al}_{52}$ から $\mathrm{Ti}_{55} \mathrm{Al}_{45}$ ま では $\gamma$ 相と $\alpha_{2}$ 相の 2 相となっているが, Tiリッチになる ほど $\alpha_{2}$ の回折ピークは高くなる. また, 焼結体の表 面には発熱体及び炉体（カーボン）からの炭素の侵入に よると考えられるTi-Al系の炭化物のピークが検出さ れた. Fig. 3 は焼結体のX線マ㐰叶ラ价゙ーによる反射 電子線像である. $\mathrm{Ti}_{5}{ }_{5} \mathrm{Al}_{4} 5$ は $\gamma / \alpha{ }_{2}$ のラメラ（層状） 組織, $\mathrm{Ti}_{5} \mathrm{Al}_{48}$ と $\mathrm{Ti}_{5} \mathrm{Al}_{5} 0$ はラメラ組織, $\gamma$ 相, $\alpha_{2}$ 相が混在する組織, $\mathrm{Ti}_{4}{ }_{8} \mathrm{Al}_{5}{ }_{2}$ はラメラ組織は存在 せず, $\gamma$ 相と少量の $\alpha_{2}$ 相が混在する組織, $\mathrm{Ti}_{45} \mathrm{Al}_{5} 5$ は $\gamma$ 単相組織となっている. 組織中, 黒く点在する もののなかで大きいものは空孔, 小さいものは酸化

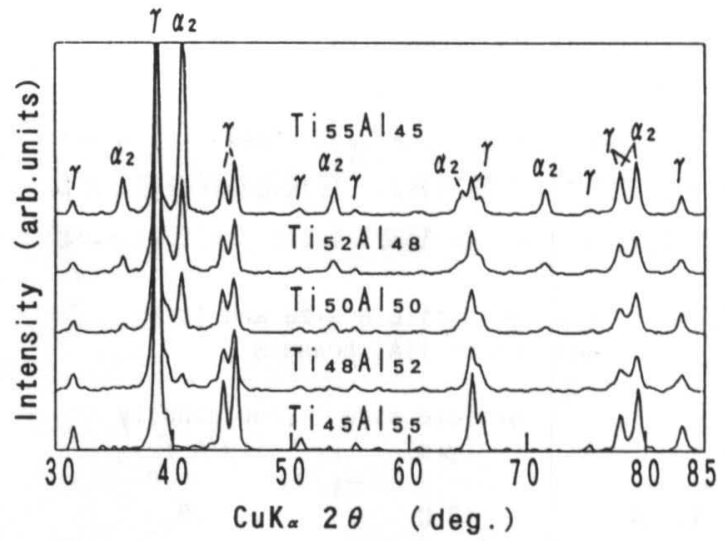

Fig.2 X-ray diffraction patterns of sintered $\mathrm{Ti}_{5} \mathrm{Al}_{45}, \mathrm{Ti}_{5} \mathrm{Al}_{48}, \mathrm{Ti}_{50} \mathrm{Al}_{50}, \mathrm{Ti}_{48} \mathrm{Al} \mathrm{I}_{2}$ and $\mathrm{Ti}_{45} \mathrm{Al}_{55}$ compacts.

物 $\left(\mathrm{Al}_{2} \mathrm{O}_{3}\right)$ である.さらに、これらを明瞭にするた めにX線マ佲叶ラ价゙ーにより凹凸の様子を調べた （Fig. 4）. 空孔は完全に独立球状化している様子が 観察される. $\mathrm{Ti}_{45} \mathrm{Al}_{5} \mathrm{H}_{5}$ から $\mathrm{Ti}_{52} \mathrm{Al}_{48}$ までの組織中に 微細に分布しているのが $\mathrm{Al}_{2} \mathrm{O}_{3}$ である. 詳細に見ると， $\mathrm{Ti}$ リチによなるほど $\mathrm{Al}_{2} \mathrm{O}_{3}$ 粒子の量は減少し, $\mathrm{Ti}_{5}{ }_{5} \mathrm{Al}_{4} 5$ にはほとんど存在しない，Tiリッチになるほど $\alpha_{2}$ 相が 増大するが, この $\alpha_{2}$ 相は酸素固溶量が高いため ${ }^{3)}$,
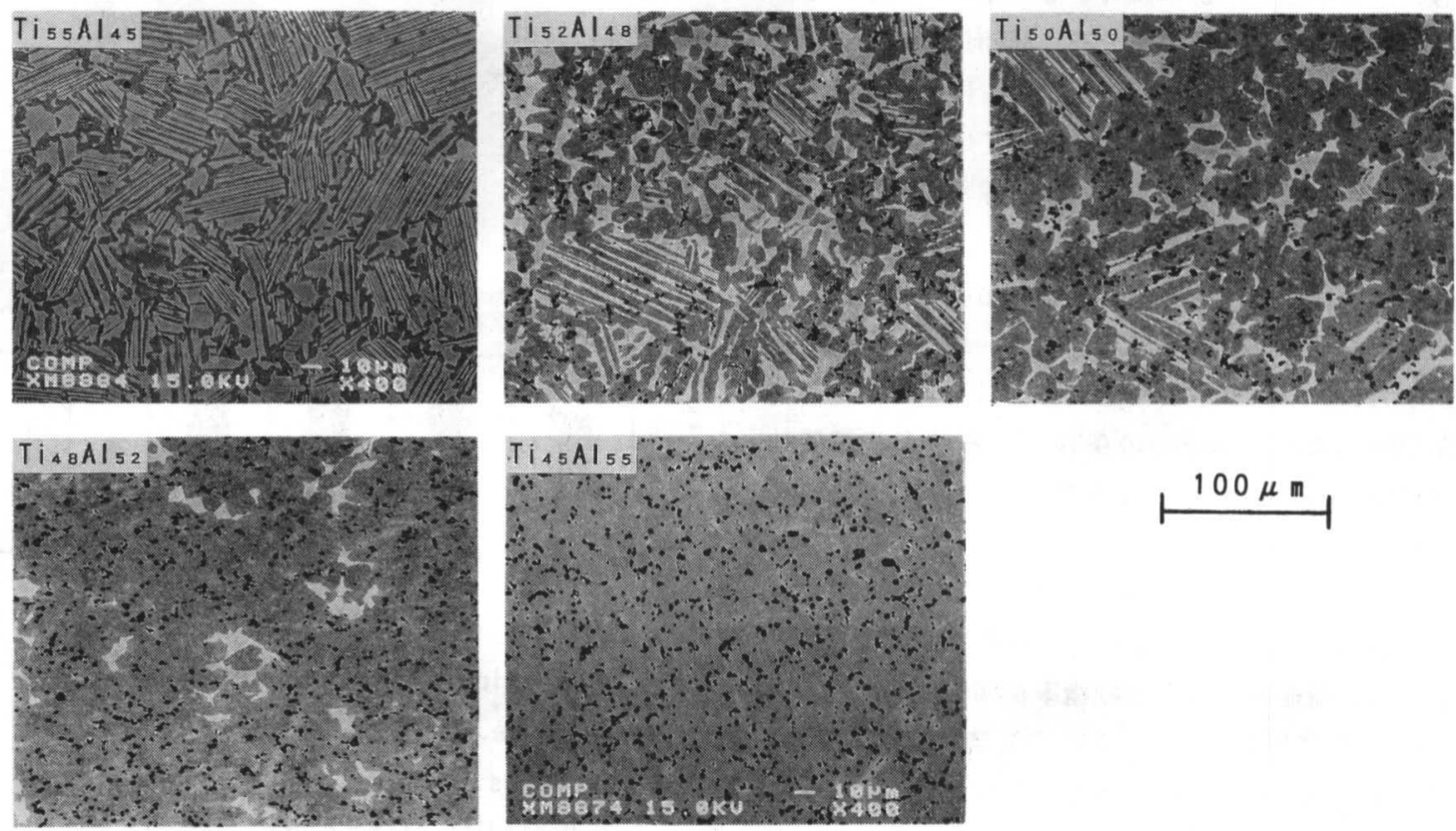

Fig. 3 Compo images of sintered TiAl compacts by XMA. 

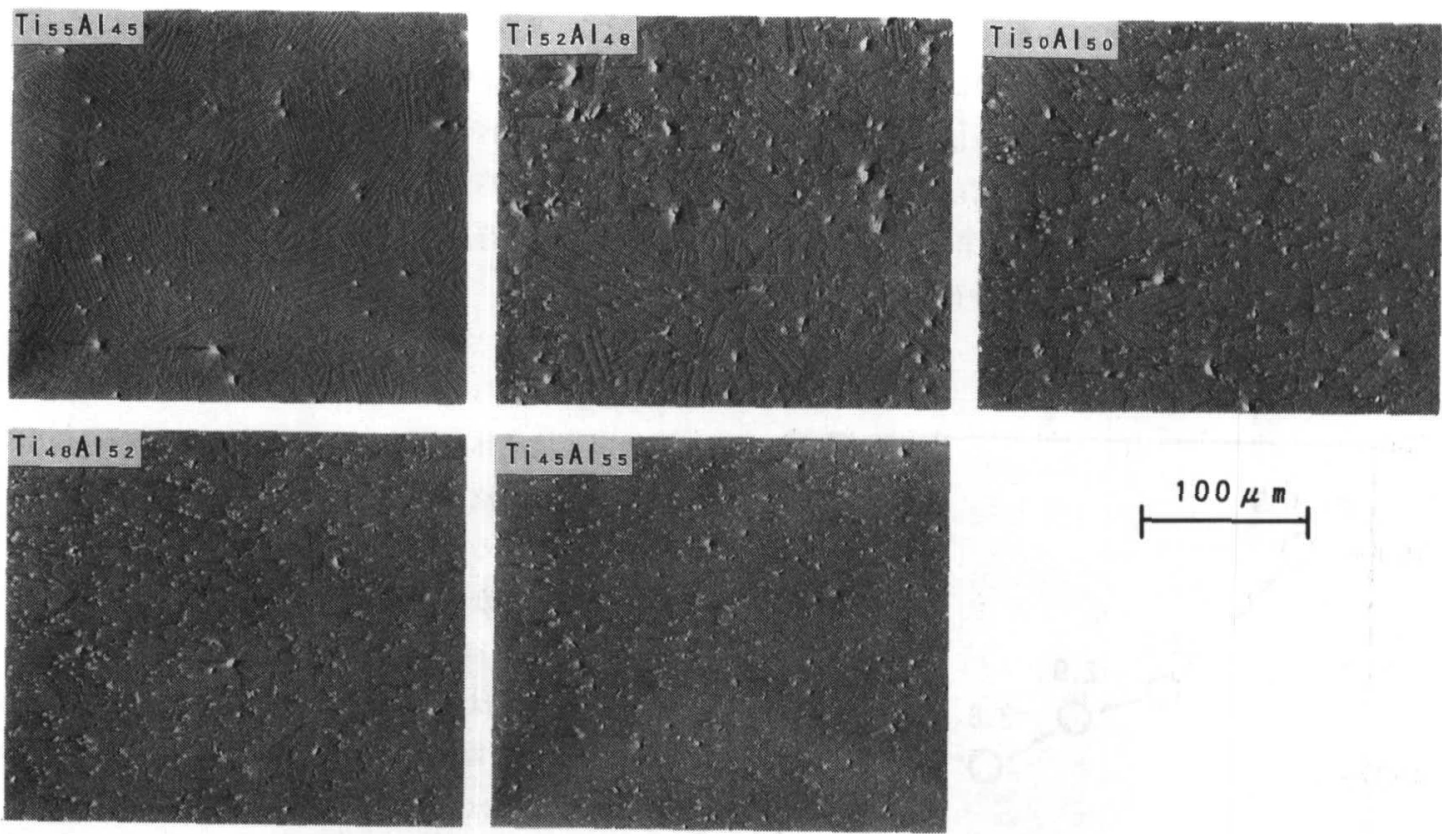

Fig.4 Uneven images of sintered TiAl compacts by XMA.

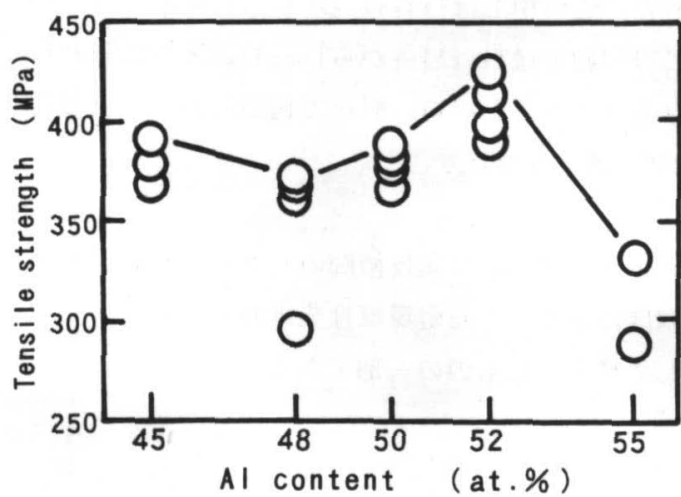

Fig.5 Relation between the tensile strength and the $\mathrm{Al}$ content of sintered TiAl compacts.

酸化物の生成が減少したと考えられる.

\section{3 室温の機械的性質}

Fig. 5 は室温での引張試験における破断強度の値 を示したものである. 同一条件で $3 \sim 4$ 本の試験を 行った. 強度に関しては $\mathrm{Ti}_{4}{ }_{5} \mathrm{Al}_{5}{ }_{5}$ 以外は $\mathrm{Ti}_{5} \mathrm{Al}_{4} \mathrm{Al}_{8}$ の 1 点を除いて比較的安定した值になった. $\mathrm{Ti}_{45} \mathrm{Al}_{55}$ は強度が他に比べて低くしかもばらついているが

$\left(\mathrm{Ti}_{45} \mathrm{Al}_{55}\right.$ の残りの 1 点は $\left.135 \mathrm{MPa}\right)$, 相対密度が低 いため材料の特性之は断定できない，すなわち，引 張りでは大きい空孔が存在するとこれが起点となり

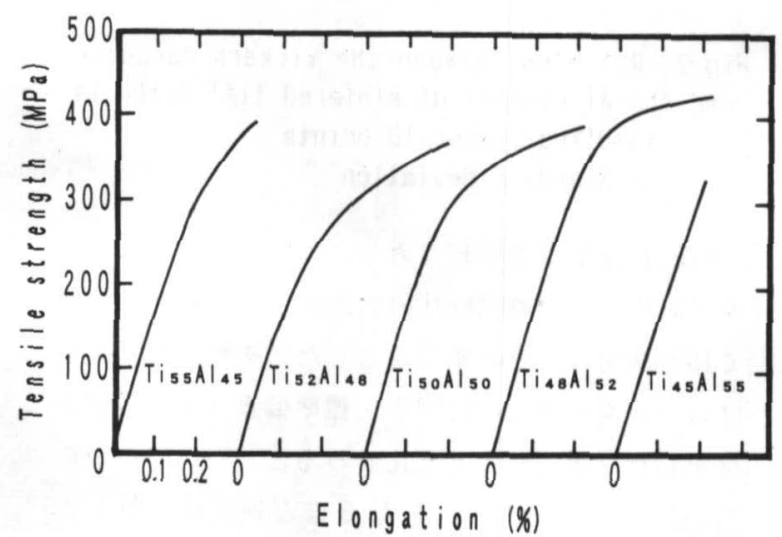

Fig.6 Strength-elongation curves of sintered TiAl compacts by tensile test.

破断に至る可能性が大きいからである. $\mathrm{Ti}_{5}{ }_{5} \mathrm{Al}_{4}{ }_{5}$ から $\mathrm{Ti}_{48} \mathrm{Al}_{52}$ までは $350 \sim 400 \mathrm{MPa}$ 程度の強度となった，2 元系TiAl溶製材の室温引張強度はこれまで報告され ているもので概ね400〜500MPaの簌囲である ${ }^{4)}$. 試験 条件等が異なるため比較は難しいが，本研究による TiAlは内部に空孔を含むため, 溶製材より幾分強度 が低いと考えられる. $\mathrm{Ti}_{48} \mathrm{Al}_{52}$ は $400 \mathrm{MPa}$ 以上の強度 も得られ，最も高くなっているが、これはラメラ組 織が存在しないためと考えられる5).

Fig. 6 は引張時の強度一伸び曲線を示したもので 
ある．化学量論組成近傍の $\mathrm{Ti}_{52} \mathrm{Al}_{48} \sim \mathrm{Ti}_{48} \mathrm{Al}_{52}$ はい ずれも $0.5 \%$ 程度の伸びを示し，塑性域に入ってから 破断しているが, $\mathrm{Ti}_{55} \mathrm{Al}_{45}$ とTi ${ }_{45} \mathrm{Al}_{55}$ はほとんど望 性変形せずに破断している。この原因は明らかでは ないが，Ti55A145はラメラ組織の著しい発達， $\mathrm{Ti}_{45} \mathrm{Al}_{55}$ は相対密度が低いこと及び酸化物の生成量 が多いことが原因と推定される。

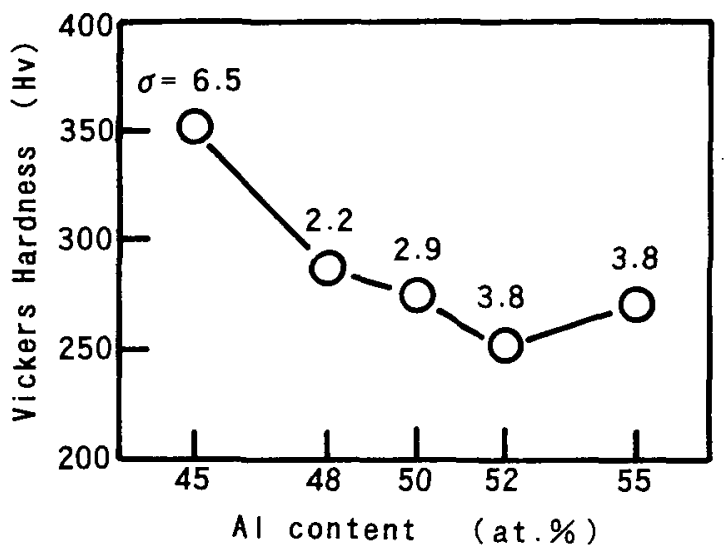

Fig. 7 Relation between the vickers hardness and the Al content of sintered TiAl compacts. Sampling number: 10 points $\sigma:$ Standard deviation

Fig. 7 は室温でのビッカース硬度の值を示したも のである，一つの試験片の引張測定部を表裹あわせ て10点測定し，その平均值とした。 また，データの ばらつきを示すために図中に標準偏差（ $\sigma ）$ の値を 付記した，組成による変化をみると， $\mathrm{Ti}_{48} \mathrm{~A} \mathrm{~A}_{52}$ 吕ら Ti汭A145まではTiリォチになるほど硬度は上昇し， $\mathrm{Ti}_{48} \mathrm{Al}_{52}$ で約 $250, \mathrm{Ti}_{5} \mathrm{fAl}_{45}$ で約 350 の值を示している.

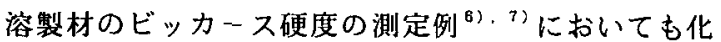
学量論組成近傍の組成が最も硬度が低く，Ti/A1に対 する硬度の変化は本研究によるものと概ね類似して いる. しかし、 $\mathrm{Ti}_{5} 0 \mathrm{~A} 1_{50}$ 溶製材の值は 200 程度である ことを考えれば，本研究による焼結体の硬度は高い 傾向にある．この原因は焼結体の $\gamma$ と $\alpha_{2}$ に含まれる 酸素量が高いこど) 及び微細酸化物の存在(A1リッ千侧) 之推定される。このような機械的特性に及ぼす酸素 や酸化物の影響については, 今後, 室温のみならず 高温での強度特性を調查した上で，詳細に検討する 予定である。

\section{4 結 言}

$\mathrm{Ti} / \mathrm{A} 1$ 比の異なる 5 種類の $\mathrm{TiAl}$ 粉末（ $\mathrm{Ti}_{5} \mathrm{SAl}_{45}$, $\left.\mathrm{Ti}_{5} \mathrm{Al}_{48}, \mathrm{Ti}_{50} \mathrm{Al}_{50}, \mathrm{Ti}_{48} \mathrm{Al}_{52}, \mathrm{Ti}_{45} \mathrm{Al}_{55}\right)$ を原料とし て，粉末射出成形法より，成形・焼結を行い，焼結 体の特性評価を行った，得られた結果を要約すると 次のようになる.

（1）真空脱脂後, $1648 \mathrm{~K} \cdot 7.2 \mathrm{ks}$ の真空焼結により, $\mathrm{Ti}_{55} \mathrm{Al}_{45}$ から $\mathrm{Ti}_{48} \mathrm{Al}_{52}$ までは相対密度 $96.5 \%$ 以上 の緻密な焼結体が得られたが，AlリッチのTi $45 \mathrm{Al}_{55}$ は $94.5 \%$ とやや焼結性が劣った．いずれの組成でむ， 大気脱脂による焼結体は真空脱脂によるものと比 較して、密度が低い傾向となった。

（2）焼結後の組織を分析した結果，Ti $55 \mathrm{Al}_{45}$ から $\mathrm{Ti}_{48} \mathrm{Al}_{52}$ までは $\left(\gamma+\alpha_{2}\right)$ の 2 相組織, $\mathrm{Ti}_{45} \mathrm{Al}_{55}$ は $\gamma$ の単相組織となった。また， Ti $5_{5} \mathrm{Al}_{45}$ 方ら

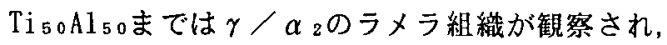
とくにTi ${ }_{5} \mathrm{Al}_{45}$ はすべてラメラ組織となった。

（3）室温での引張り試験の結果, Tis5A145から $\mathrm{Ti}_{48} \mathrm{Al}_{52}$ までは350 400MPa程度の破断強度が得ら れた。この中ではTi ${ }_{48} \mathrm{Al}_{52}$ が最も高強度となった。

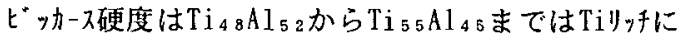
なるほど上昇し， $\mathrm{Ti}_{48} \mathrm{Al}_{5}$ で約 $250, \mathrm{Ti}_{5} \mathrm{Al}_{45}$ で約 350の值となった。

本研究は通産省工業技術院の産業科学技術研究開 発制度に基づく「超耐環境性先進材料」の 1 テーマ として行われたものの一部である.

\section{文 献}

1）加藤清隆，野崎佳彦，松本章宏：粉体および粉 末冶金，39(1992）875.

2 ）村松祐治，大越恒雄，营広雄：日本金属学会誌， 57(1993) 944.

3) 加藤清隆,松本章宏, 野崎佳彦: 第 4 回超耐環境 性先進材料シッポジ方講演集, (財)次世代金属・複 合材料研究開発協会，(財)日本産業技術振興協会 発行, (1993) 178 .

4）山口正治：金属， 1(1989）49.

5 ) 横手隆昌, 目秦将志: 日本金属学会講演概要 (第109回), (1991) 332 .

6 ) 磯部 晋: 素形材, 3(1989) 1 .

7 ）辻本得蔵，橋本健紀，信木稔，菅広雄：日本金 属学会誌, 48(1984) 435 . 